\title{
Effects of Metal-Organic Chemical Vapour Deposition grown seed layer on the fabrication of well aligned ZnO nanorods by Chemical Bath Deposition
}

\author{
Maria Elena Fragalà a,*, Yana Aleeva ${ }^{b}$, Graziella Malandrino ${ }^{\text {a }}$ \\ a Dipartimento di Scienze Chimiche Università di Catania and INSTM UdR Catania, Viale Andrea Doria,6, Catania, Italy \\ b Scuola Superiore Università di Catania, Dipartimento di Scienze Chimiche Viale Andrea Doria,6, Catania, Italy
}

\section{A R T I C L E I N F O}

Article history:

Received 14 September 2010

Received in revised form 11 May 2011

Accepted 17 May 2011

Available online 25 May 2011

\section{Keywords:}

Metal-Organic Chemical Vapour Deposition

Chemical Bath Deposition

Zinc oxide

Nanorods

Scanning Electron Microscopy

\begin{abstract}
A B S T R A C T
Well aligned, long and uniform $\mathrm{ZnO}$ nanorods have been reproducibly fabricated adopting a two-steps MetalOrganic Chemical Vapour Deposition (MOCVD) and Chemical Bath Deposition (CBD) fabrication approaches. Thin $(<100 \mathrm{~nm}) \mathrm{ZnO}$ buffer layers have been seeded on silicon substrates by MOCVD and ZnO layers have been subsequently grown, in form of well textured nanorods, using CBD. It has been found that the structure and thickness of the seed layer strongly influence the final morphology and the crystal texturing of ZnO nanorods as well as the CBD growth rate. There is, in addition, a strong correlation between morphologies of $\mathrm{CBD}$ grown $\mathrm{ZnO}$ nanorods and those of the seed layer underneath. Thus, nanorods deposited over low temperature MOCVD buffer layers are less homogeneous in lateral dimensions and poorly vertically oriented. On the contrary, higher temperature nano-dimensional ZnO seeds favour the CBD growth of almost monodimensional homologue nanorods, with an adequate control of the lateral transport of matter. The nanorod aspect ratio values decrease upon increasing the deposition temperatures of the seed layers. Moreover, the nanorods length can be tailored either by adjusting the CBD growth time or by changing concentration of the $\mathrm{N}, \mathrm{N}, \mathrm{N}^{\prime}, \mathrm{N}^{\prime}$-tetramethylethylenediamine ligand used in the CBD process. In particular, at high concentrations, the $\mathrm{CBD}$ process is faster with a greater global aspect ratio in agreement with a preferential one-dimensional growth of the $\mathrm{ZnO}$ nanostructures. Finally, these $\mathrm{ZnO}$ nanorod arrays possess good optical quality in accordance to the photoluminescence properties.
\end{abstract}

(c) 2011 Elsevier B.V. All rights reserved.

\section{Introduction}

$\mathrm{ZnO}$ nanostructures are catalysing considerable scientific attention for application spanning from energy storage and conversion devices to biomedical sensors [1]. In particular, nanorods, nanowires and, more generally, one-dimensional (1-D) nanostructures possess unique properties and a large surface to volume ratio that offer a great potential for advanced and highly efficient nano-devices [1,2].

A large variety of techniques has been proposed to fabricate vertically aligned $\mathrm{ZnO}$ nanostructures. Nevertheless, the present technological demand presses toward flexible, low cost, easily scalable and reproducible approaches and solution methods involving liquid phase deposition strategy become appealing for their simple apparatus and low temperature requirements. These, however, still lack of suited uniformity control, especially on the large scale. Lately, homoepitaxial routes have proven well suited for $\mathrm{ZnO}$ nanoarrays formation using homologous seed layers to promote the uniform growth of oriented nanorods from aqueous solutions. In fact, despite hydrothermal [3]

\footnotetext{
* Corresponding author at: Dipartimento di Scienze Chimiche, Università di Catania Viale Andrea Doria, 6, 95127 Catania, Italy. Tel.: + 39095 7385055; fax: + 39 095580138.

E-mail address: me.fragala@unict.it (M.E. Fragalà).
}

procedures are capable of $\mathrm{ZnO}$ growth without seed layers, most of the literature, related to solution approaches, has been focused on the use of homoepitaxial ZnO seed layer, such as crystals or thin films [4-7]. The presence of nucleation sites lowers the energy barrier in Chemical Bath Deposition (CBD), improves the aspect ratio of the obtained nanorods $[5,6]$ and favours a better uniformity [7].

Seed layers deposited over various substrates by drop casting, sputtering or spin coating of $\mathrm{Zn}$ sols onto the substrates with a following post-annealing, favour $\mathrm{ZnO}$ crystal growth. Similarly, the decomposition of zinc acetate has been proposed to produce nucleation sites for $\mathrm{ZnO}$ nanowires [8,9]. Moreover, it has been shown that pre-coating of glass and silicon substrates via sol-gel/spin coating [9-13], annealing of either Radio Frequency (RF) sputtered [14] or Metal-Organic Chemical Vapour Deposition (MOCVD) [15-17] deposited seed layers enhances texturing and crystallinity and is crucial for the formation of aligned $\mathrm{ZnO}$ nanowire/nanorod overlayers with improved properties.

The present paper presents a systematic study of effects of morphologies of $\mathrm{ZnO}$ seed layers, deposited via MOCVD on $\mathrm{Si}$ substrates in a wide temperature ranges $\left(300{ }^{\circ} \mathrm{C}-600{ }^{\circ} \mathrm{C}\right.$ ) and deposition times (10 min-60 min), on the properties of $\mathrm{ZnO}$ nanorods fabricated using a following CBD process.

We will demonstrate that thickness uniformity, crystallinity and morphology of the $\mathrm{ZnO}$ seed layer can be easily and accurately 

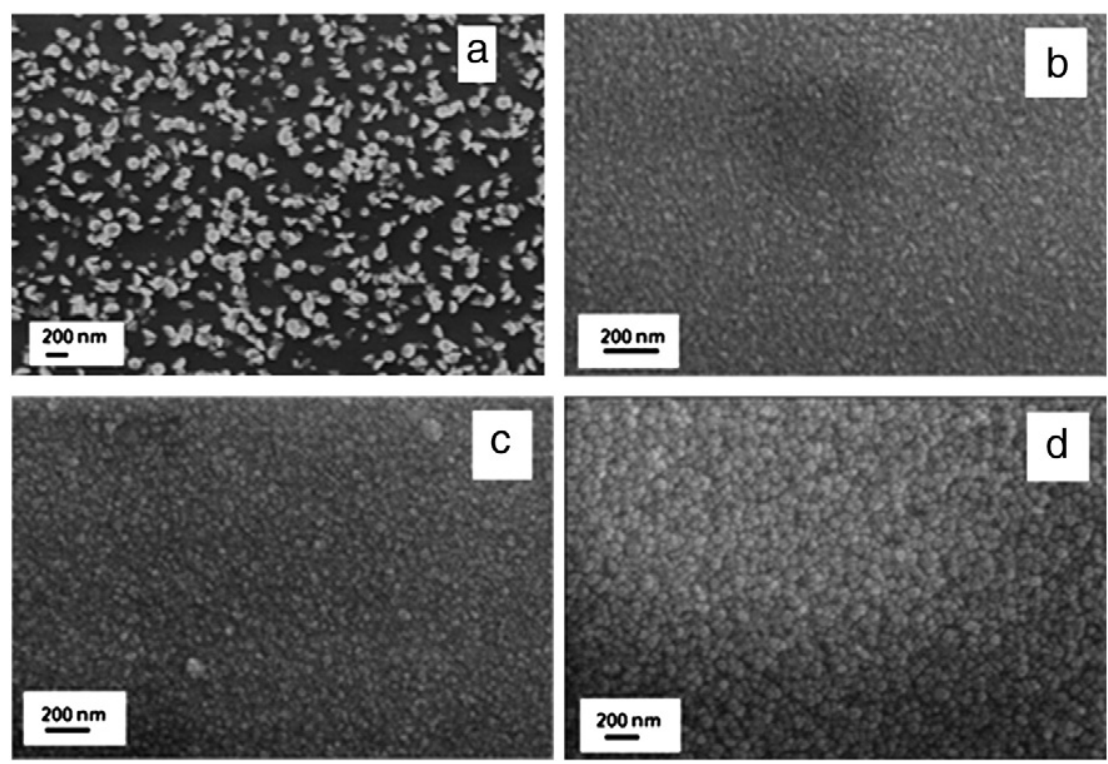

Fig. 1. SEM images of $\mathrm{ZnO}$ buffer layers deposited on Si substrates by MOCVD at $300{ }^{\circ} \mathrm{C}$ (a), $400{ }^{\circ} \mathrm{C}$ (b), $500{ }^{\circ} \mathrm{C}(\mathrm{c})$ and $600{ }^{\circ} \mathrm{C}(\mathrm{d})$.

controlled in a simple MOCVD process to form tunable templates for growing $\mathrm{ZnO}$ nanorods from solutions. An accurate control of orientation, morphology, growth density, diameter distribution and crystallinity of ZnO nanoarrays has been obtained with both a good caxis texturing and a high crystal quality in accordance with a strong emission in the UV region.

\section{Experimental details}

The deposition of ZnO buffer layer on silicon substrates has been performed in a hot wall tubular reactor, using a diamine $\left(\mathrm{N}, \mathrm{N}, \mathrm{N}^{\prime}, \mathrm{N}^{\prime}-\right.$ tetramethylethylenediamine) (TMEDA) adduct of Zinc(II)bis(2thenoyl-trifluoroacetonate) [herein $\mathrm{Zn}(\mathrm{tta})_{2} \cdot t$ tmeda] [18]. Silicon substrates have been etched in HF for $60 \mathrm{~s}$ in order to remove the surface native oxide, washed with water and blown with nitrogen. The substrate temperature has been varied in the $300{ }^{\circ} \mathrm{C}-600{ }^{\circ} \mathrm{C}$ range and deposition times investigated in the 10-60 min range. $\mathrm{Ar}$
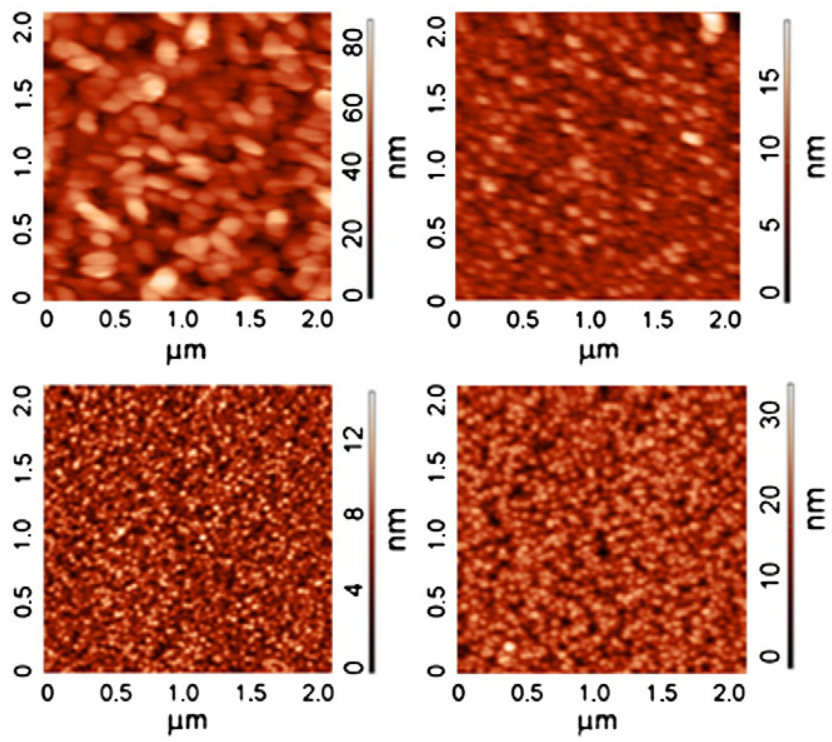

Fig. 2. AFM images of $\mathrm{ZnO}$ buffer layers deposited on $\mathrm{Si}$ substrates by MOCVD at $300{ }^{\circ} \mathrm{C}$ (a), $400{ }^{\circ} \mathrm{C}$ (b), $500{ }^{\circ} \mathrm{C}(\mathrm{c})$ and $600{ }^{\circ} \mathrm{C}(\mathrm{d})$.
(250 sccm) and $\mathrm{O}_{2}(250 \mathrm{sccm})$ have been used as carrier and reactive gas respectively.

The precursor solutions used for CBD growth have been prepared by mixing $\mathrm{Zn}\left(\mathrm{CH}_{3} \mathrm{COO}\right)_{2} \cdot 2 \mathrm{H}_{2} \mathrm{O}$ with TMEDA water solutions whilst keeping a 1:1 constant volume ratio [19]. All chemicals were of analytical reagent grade and used without further purification. Experiments focused on effect of concentration, were performed by keeping constant the volume ratio of the two solutions for any concentrations studied. The CBD growth has been carried out at $70{ }^{\circ} \mathrm{C}$ by dipping the pre-treated substrates in a glass beaker for fixed time periods.

The morphology and size of $\mathrm{ZnO}$ nanorods have been studied by Field Emission Scanning Electron Microscopy (FE-SEM) using a ZEISS VP 55 microscope. $\theta-2 \theta$ X-Ray Diffraction (XRD) analyses have been made using a Bruker-AXS D5005 $\theta-\theta$ X-ray diffractometer with $\mathrm{Cu} \mathrm{K}_{\alpha}$ radiation operating at $40 \mathrm{kV}$ and $30 \mathrm{~mA}$. Atomic Force Microscopy (AFM) images have been obtained in contact mode in air with an NTMTD instrument. The root mean-square roughness determined by AFM has been calculated from $(2 \times 2) \mu \mathrm{m}^{2}$ area.

Room temperature photoluminescence $(\mathrm{PL})$ measurements have been performed using a $325 \mathrm{~nm}$ He-Cd laser with a $2.5 \mathrm{~W} / \mathrm{cm}^{2}$ incident power density. The PL spectra have been recorded with a monochromator fitted with 1800 grooves/mm grating and a photomultiplier tube.

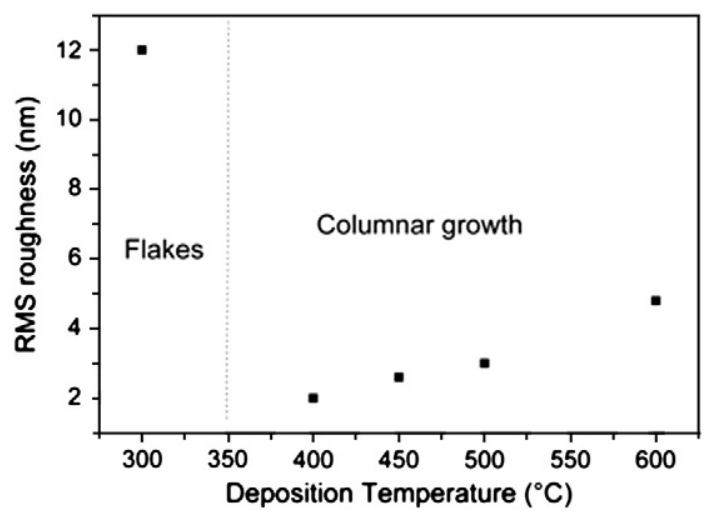

Fig. 3. Root Mean Square (RMS) roughness of ZnO buffer layers vs MOCVD deposition temperature. 


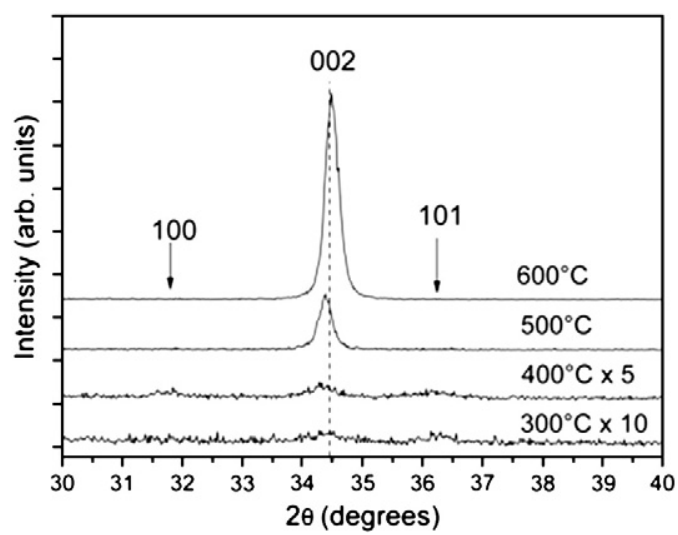

Fig. 4. XRD patterns of ZnO buffer layers obtained by MOCVD at different temperatures.

\section{Results}

\subsection{ZnO buffer layer MOCVD deposition}

It is well known that $\mathrm{CBD}$ growth of $\mathrm{ZnO}$ nanorods overlayers requires uniform and well oriented seeds and, therefore, involves stringent requirements to favour one-dimensional monocrystal growth without lateral transport of matter [20-22]. Several seeding strategies including sol-gel spin coating or dip-coating (followed by high temperature treatments) and physical methods $[14,20]$ have been used. By contrast, Chemical Vapour Deposition, has been poorly investigated despite it represents a low cost, viable, easily and tuneable, conformal route. Some systematic studies have investigated effects of thermal annealing treatments of MOCVD ZnO buffer layers in the perspective of improving the properties of the subsequently deposited CBD ZnO main layer [16,17]. Nevertheless, systematic effects upon varying MOCVD parameters have not been scrutinised.

In this general scenario we have investigated $\mathrm{ZnO}$ buffer layers deposited in a low pressure hot-wall MOCVD reactor within a
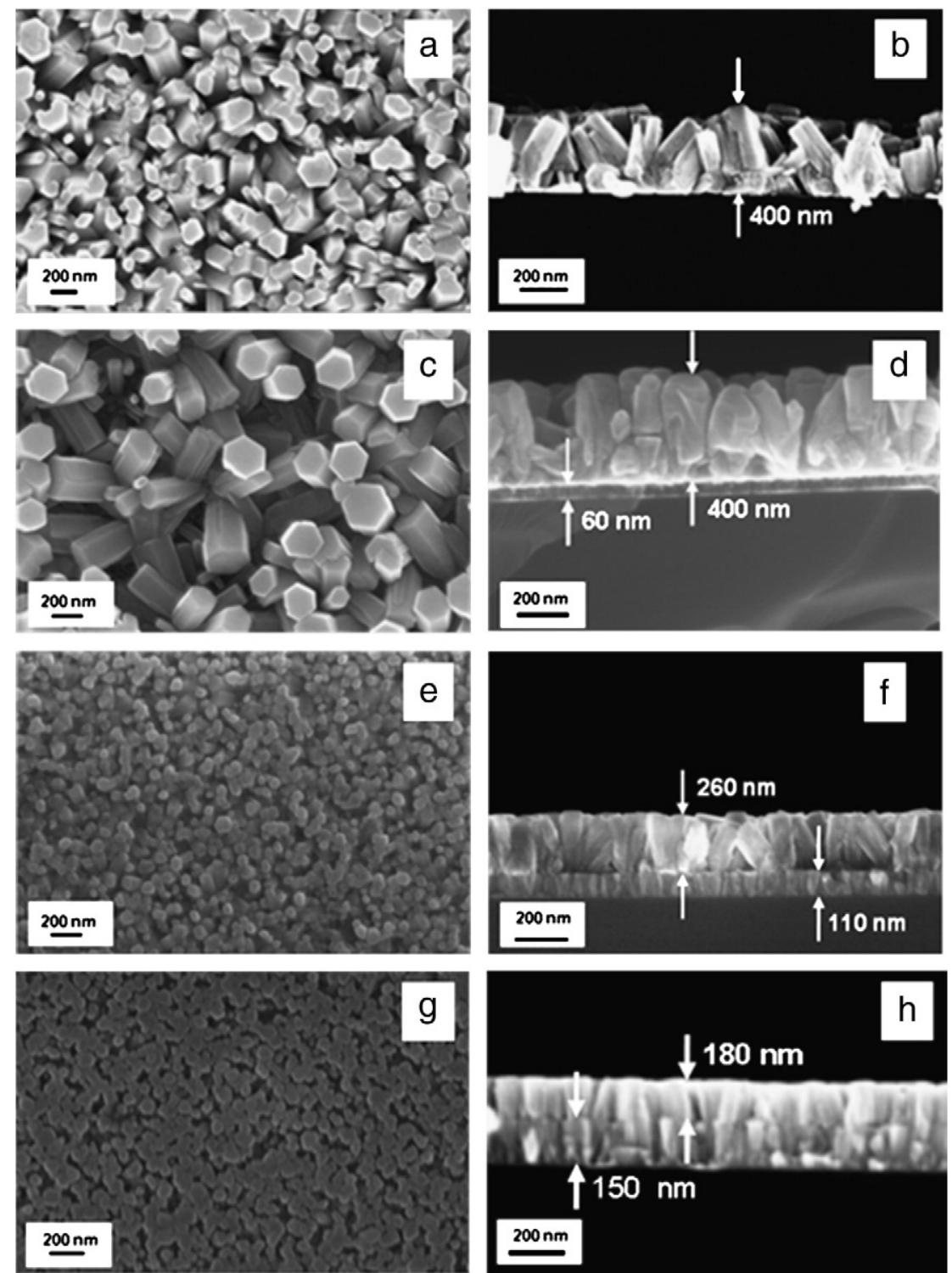

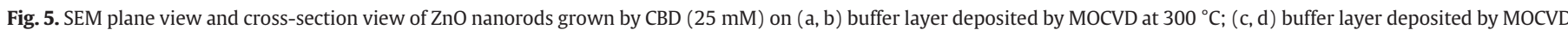
at $400{ }^{\circ} \mathrm{C}$; (e, f) buffer layer deposited by MOCVD at $500{ }^{\circ} \mathrm{C}$; and $(\mathrm{g}, \mathrm{h})$ buffer layer deposited by MOCVD at $600{ }^{\circ} \mathrm{C}$. 


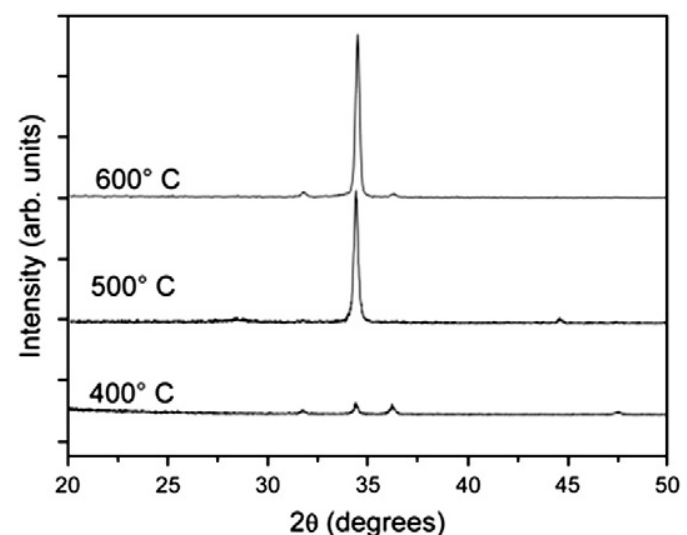

Fig. 6. XRD patterns of $\mathrm{ZnO}$ nanorods grown by $\mathrm{CBD}$ ( $25 \mathrm{mM}, 2 \mathrm{~h}$ ) on $\mathrm{ZnO}$ buffer layers grown by MOCVD.

$300{ }^{\circ} \mathrm{C}-600{ }^{\circ} \mathrm{C}$ temperature range using $\mathrm{Zn}(\mathrm{tta})_{2} \cdot$ tmeda as $\mathrm{Zn}$ precursor. Although deposition temperature represents the most critical parameter of any CVD process, both the precursor evaporation temperature and the $\mathrm{O}_{2}$ reacting gas partial pressure, have been expedient to tailor structure, morphology and properties of growing seed films. Preliminary experiments [23] have clearly demonstrated that best clean and pure $\mathrm{ZnO}$ films require setting of the evaporation source temperature at $170{ }^{\circ} \mathrm{C}$ and of the $\mathrm{O}_{2}$ reacting gas at $250 \mathrm{sccm}$.

Deposition temperatures affect the morphologies and crystal structures of $\mathrm{ZnO}$ buffer layers. SEM analysis provides evidence (Fig. 1a) that $\mathrm{ZnO}$ growth proceeds through an island growth mode. At low temperature $\left(300^{\circ} \mathrm{C}\right)$ a discontinuous film structure,
Table 1

Dimensions and growth rates of $\mathrm{ZnO}$ nanorods vs TMEDA concentration.

\begin{tabular}{lccc}
\hline$[$ TMEDA] $(\mathrm{mM})$ & $\mathrm{d}(\mathrm{nm})$ & $\mathrm{l}(\mathrm{nm})$ & Growth rate $(\mathrm{nm} / \mathrm{h})$ \\
\hline 15 & 60 & 530 & 90 \\
25 & 80 & 850 & 140 \\
50 & 100 & 1150 & 190 \\
\hline
\end{tabular}

characterised by hexagonal flakes, is well evident. As the temperature increases, in particular in the $400{ }^{\circ} \mathrm{C}-600{ }^{\circ} \mathrm{C}$ range, the films become continuous due to coalescence of islands and the granular structure changes from smaller (Fig. 1b) to larger and more geometrically defined grains (Fig. 1c and d). The inferred thickness ranges from $\sim 50 \mathrm{~nm}$ for the samples deposited at $400{ }^{\circ} \mathrm{C}$ to $\sim 150 \mathrm{~nm}$ for those deposited at $600{ }^{\circ} \mathrm{C}$. The thickness of samples deposited at $300{ }^{\circ} \mathrm{C}$ can be hardly detected due to the flaky nature of the layer.

The AFM analyses (Fig. 2) are closely tuned to SEM morphologies. There is, therefore, evidence that $300{ }^{\circ} \mathrm{C}$ represents a threshold temperature between two different MOCVD growth modes. In fact, disordered flakes are associated at this temperature with an island growth involving a partially covered substrate and, hence a high surface root mean square (RMS) roughness $(\sim 12 \mathrm{~nm})$. Above this threshold, a continuous layer becomes predominant and the smoother morphology (RMS $\sim 2-4 \mathrm{~nm}$ ) appears controlled by the deposition temperature with greater grains and related RMS values increasing parallel to the temperature evolution (Fig. 3).

This behaviour can be related to better quality films upon increasing the temperature and, hence, the mobility of adatoms over the substrate.

Under low temperature/mobility regimes, any full crystallisation is precluded in accordance with the slightly discernible XRD patterns of films deposited at $300{ }^{\circ} \mathrm{C}$ and $400{ }^{\circ} \mathrm{C}$ (Fig. 4). Note, however, that the
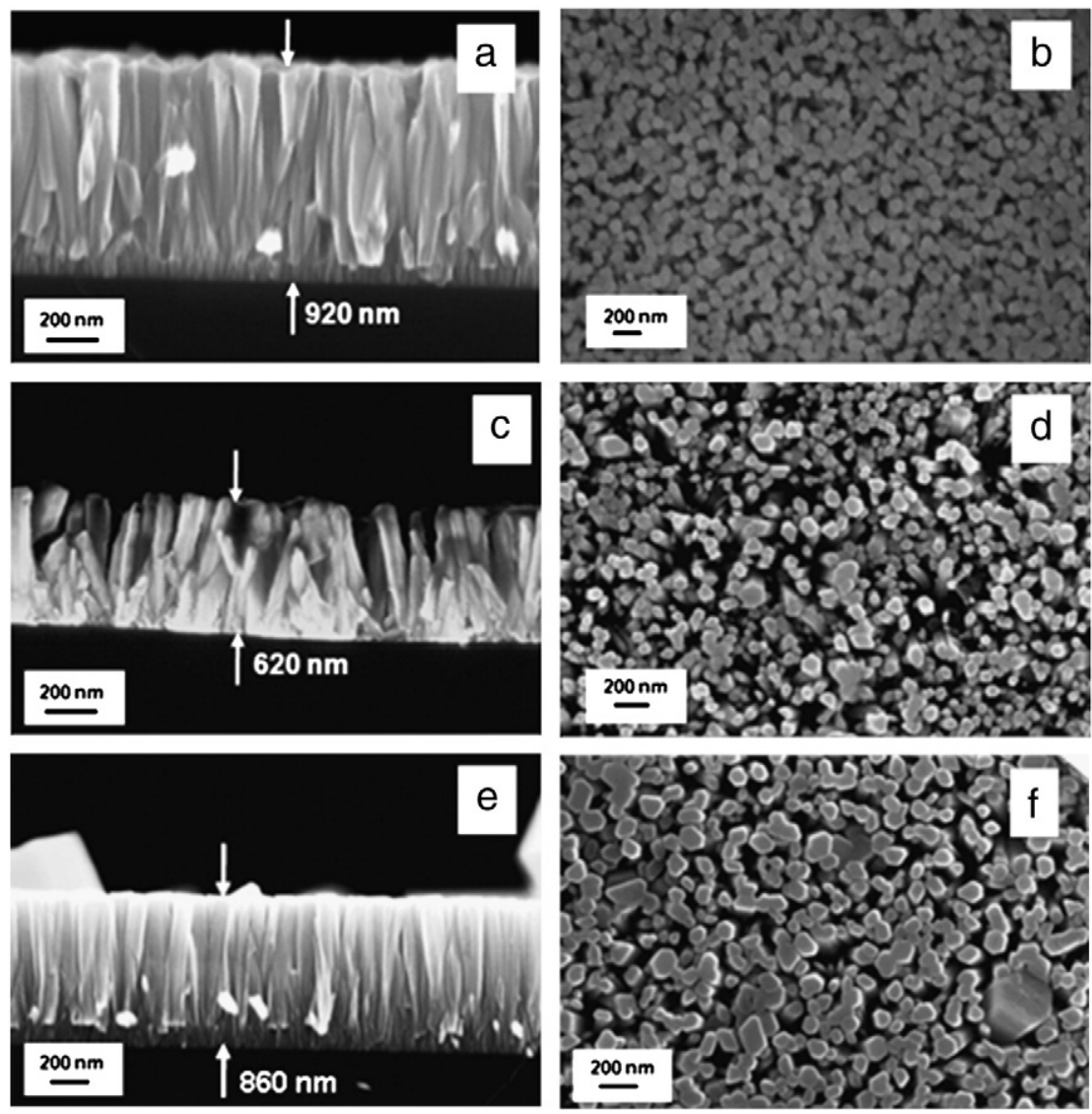

Fig. 7. SEM images of $\mathrm{ZnO}$ nanorods grown by CBD (25 mM, $6 \mathrm{~h}$ ) on buffer layer deposited by MOCVD at $500{ }^{\circ} \mathrm{C}$ for $30 \mathrm{~min}(\mathrm{a}, \mathrm{b}) ; 10 \mathrm{~min}(\mathrm{c}, \mathrm{d})$ and $60 \mathrm{~min}(\mathrm{e}, \mathrm{f})$. 

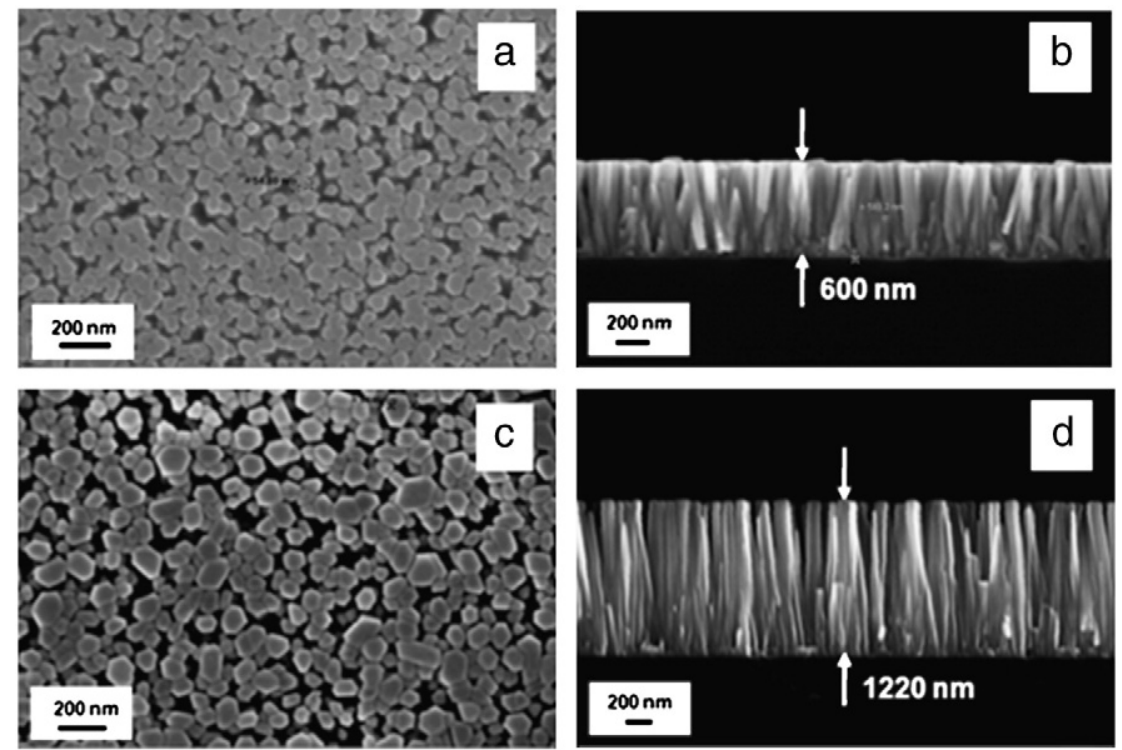

Fig. 8. SEM images of $\mathrm{ZnO}$ nanorods grown by $\mathrm{CBD}\left(6 \mathrm{~h}\right.$ on $500{ }^{\circ} \mathrm{C}, 30 \mathrm{~min}$ buffer layer) at using different TMEDA concentrations, $15 \mathrm{mM}$ (a, b) and $50 \mathrm{mM}$ (c, d).

negligible films thickness could be also considered to account for the poor XRD signal.

Upon increasing the temperature, a high mobility is favoured and adatoms arrange in well suited positions for crystal growth. Thus, at $500{ }^{\circ} \mathrm{C}$ the 002 peak $\left(2 \theta=34.40^{\circ}\right)$ becomes narrow $\left(0.3^{\circ}\right)$. The peak further shifts to $2 \theta=34.50^{\circ}$ at $600^{\circ} \mathrm{C}$, with an even narrow FWHM $\left(0.25^{\circ}\right)[15,24]$.

\section{2. $\mathrm{ZnO}$ nanorods $\mathrm{CBD}$ deposition}

The present prototypical seeded films have been subjected to a $2 \mathrm{~h}$ CBD process. Thus, equal volumes of equimolar water solution of $\mathrm{Zn}$ $\left(\mathrm{CH}_{3} \mathrm{COO}\right)_{2} \cdot 2 \mathrm{H}_{2} \mathrm{O}$ and TMEDA have been used as precursors, as described elsewhere [19]. The diamine based ligands are often used in CBD due to the dual ability to complex zinc cations $\left(\mathrm{Zn}^{2+}\right)[25]$ and undergo basic hydrolysis. The hydrolytic equilibria of related complexes control the overall $\mathrm{CBD}$ growth by a gradual release of $\mathrm{Zn}^{2+}$ and $\mathrm{OH}^{-}$reactants. At $70^{\circ} \mathrm{C}$ the dissociation equilibrium of $[\mathrm{Zn}$ $\left.(\text { TMEDA })_{n}\right]^{2+}$ is perturbed and the amino-ligand undergoes basic hydrolysis $[19,25]$

$\left[\mathrm{Zn}(\mathrm{TMEDA})_{\mathrm{n}}\right]^{2+} \leftrightarrows \mathrm{Zn}^{2+}+\mathrm{nTMEDA}$

$2 \mathrm{TMEDA}+2 \mathrm{H}_{2} \mathrm{O} \leftrightarrows 2 \mathrm{TMEDA}-\mathrm{H}^{+}+2 \mathrm{OH}^{-}$

$\mathrm{Zn}^{2+}+2 \mathrm{OH}^{-} \rightarrow \mathrm{Zn}(\mathrm{OH})_{2} \downarrow \rightarrow \mathrm{ZnO} \downarrow+\mathrm{H}_{2} \mathrm{O}$

The growing $\mathrm{ZnO}$ nanostructures show a strong correlation between their morphologies and those of the seed layer underneath. It has been discussed in the previous section that MOCVD deposition at $300{ }^{\circ} \mathrm{C}$ produces a "flake-like" $\mathrm{ZnO}$ buffer layer with an island morphology, not uniformly covering the silicon substrates. The related $\mathrm{ZnO}$ nanorods grown by CBD (Fig. 5a) are, thus, slanted and geometrically not well defined. SEM cross section images (Fig. 5b) estimate a mean diameter of $\sim 100 \mathrm{~nm}$. The seed layer is slightly visible in the cross section, due to the flaky nature and thickness discontinuity. The overall stack length is $\sim 400 \mathrm{~nm}$. On passing to $\mathrm{ZnO}$ buffer layers deposited at $400{ }^{\circ} \mathrm{C}$, the related $\mathrm{ZnO}$ nanorods have the expected hexagonal shape. The nanorods, moreover, possess a more homogeneous distribution of dimensions with an average diameter of $\sim 200 \mathrm{~nm}$ and a length of $\sim 400 \mathrm{~nm}$ (Fig. 5c and d). The seed layer is well discernible in the cross section with a thickness of about $60 \mathrm{~nm}$ (overall stack length $\sim 460 \mathrm{~nm}$ ). Despite the dense buffer layer, the $\mathrm{CBD}$ process still results in poorly vertically oriented $\mathrm{ZnO}$ nanorod arrays. This observation matches well with the low crystallinity of the buffer layer, in accordance with the XRD analysis.

By increasing the deposition temperature $\left(500{ }^{\circ} \mathrm{C}\right)$, buffer layers acquire a columnar shape with a greater thickness $(\sim 110 \mathrm{~nm})$ and crystallinity. As a consequence, the related CBD ZnO nanorods (Fig. 5e and f) appear more vertically oriented, thinner (mean diameter $\sim 100 \mathrm{~nm}$ ) and somewhat shorter $(\sim 260 \mathrm{~nm})$. In addition, due to the reduced diameter, the mean surface density (number of nanorods/surface unit) is dramatically increased and a dense $\mathrm{ZnO}$ nanorods array is formed after CBD (overall stack length of $\sim 370 \mathrm{~nm}$ ).

Finally, there is evidence that at the highest deposition temperature $\left(600{ }^{\circ} \mathrm{C}\right)$ the $\mathrm{CBD}$ process replicate a $\mathrm{ZnO}$ overlayer over the primary seeds of $\mathrm{ZnO}$ nanorods $(\sim 150 \mathrm{~nm})$ (Fig. $5 \mathrm{~g}$ and $\mathrm{h}$ ). The almost perfect matching of diameters $(\sim 100 \mathrm{~nm})$ results in final CBD grown $\mathrm{ZnO}$ nanorods of about $\sim 180 \mathrm{~nm}$ length (overall stack length $\sim 330 \mathrm{~nm}$ ).

It is worth noting that more structured seed layers results in a CBD growth of shorter and thinner $(\sim 100 \mathrm{~nm}) \mathrm{ZnO}$ nanorods as the consequence of comparable mass transport (under comparable bath

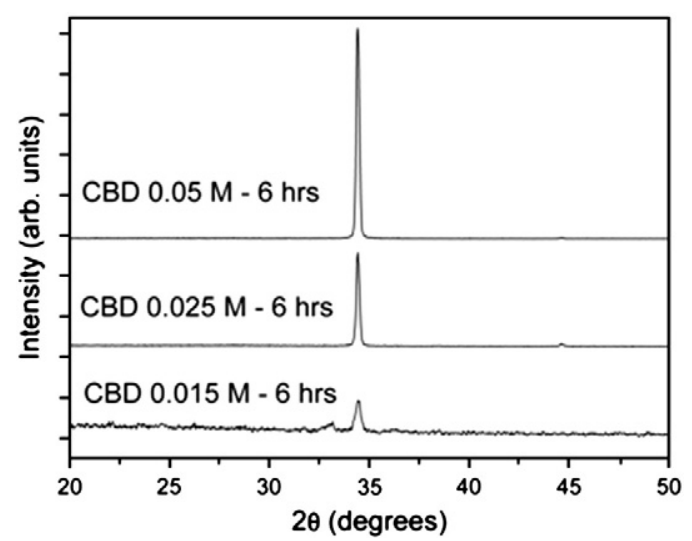

Fig. 9. XRD patterns of $\mathrm{ZnO}$ nanorods grown (CBD $6 \mathrm{~h})$ on buffer layers $\left(500{ }^{\circ} \mathrm{C}, 30 \mathrm{~min}\right)$ using different TMEDA concentrations. 


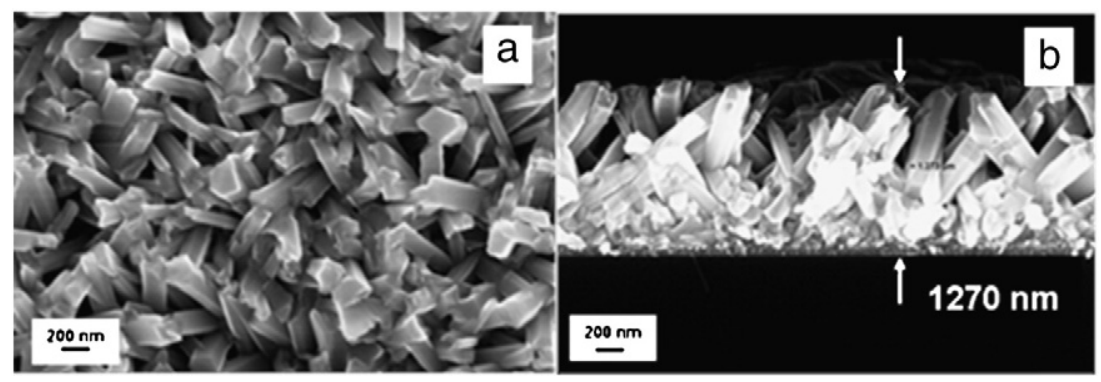

Fig. 10. SEM images of $\mathrm{ZnO}$ nanorods grown by CBD (2 h) on $\mathrm{ZnO}$ buffer layer deposited at $400{ }^{\circ} \mathrm{C}$ using 50 mM TMEDA concentration.

concentrations and growth times) over a remarkably increased number of active sites associated to greater surface roughness. Similar arguments can be invoked to understand the evolution of nanorods density upon increasing the MOCVD deposition temperatures of the $\mathrm{ZnO}$ seed layers which morphologies evolve from a granular structure to nanorods. This trend, conversely, increases both the related surfaces-to-volume ratio and the numbers of active centres responsible for the heterogeneous nucleation at the interface with the CBD solution. The final consequences are thinner nanorods and more dense structures.

Interesting enough, XRD patterns (Fig. 6) provide evidence of the influence of the crystallographic nature of underlying layers on c-axis texturing of CBD nanostructures upon increasing the MOCVD deposition temperature. In particular, both, the better orientation and crystallisation of the seed layer, favour a higher 002 texturing of CBD ZnO nanorods.

The length of neo formations can be modulated by prolonged CBD treatments. Thus, after $6 \mathrm{~h} \mathrm{ZnO}$ CBD growth, over a buffer deposited at $500{ }^{\circ} \mathrm{C}$, for $60 \mathrm{~min}$ (thickness $\sim 110 \mathrm{~nm}$; Fig. 5e and f) produces $750 \mathrm{~nm}$ long nanorods (vide infra), whilst after $8 \mathrm{~h}$ the length increases up to $1 \mu \mathrm{m}$ (not shown).

Moreover, a strong correlation has been presently found between the seed layer thickness and the CBD growth rate. Thus, ZnO buffer layers deposited by MOCVD at $500{ }^{\circ} \mathrm{C}$ for $30 \mathrm{~min}$ (Fig. 7a and b) and $10 \mathrm{~min}$ (Fig. 7c and d) have been subjected to $6 \mathrm{~h} \mathrm{CBD}$ growth and the length of the obtained $\mathrm{ZnO}$ nanorods has been compared to that obtained on the buffer layer deposited at the same temperature, for $1 \mathrm{~h}$ (Fig. 7e and f). It has been observed that reduction of the MOCVD deposition time (30 min) results in a $\sim 70 \mathrm{~nm}$ thick seed layer with an overall length of $\mathrm{ZnO}$ nanorods increased to $850 \mathrm{~nm}$ (vs $750 \mathrm{~nm}$ obtained on thicker seed layer deposited for $1 \mathrm{~h}$, Fig. 7e and f) and the density of the $\mathrm{ZnO}$ nanorods similarly increased. The further reduction of the seeding time to $10 \mathrm{~min}$ certainly causes a thinner and not uniform buffer layer (not detectable in the SEM cross section image), leading to a reduction of the $\mathrm{CBD}$ growth rate. Therefore, the $\mathrm{ZnO}$ nanorods growth (Fig. 7c and d) over high temperature $\left(500{ }^{\circ} \mathrm{C}\right.$ ) buffer layer for short deposition time $(10 \mathrm{~min})$ resembles that obtained on seeds deposited at lower temperature $\left(300{ }^{\circ} \mathrm{C}\right.$, Fig. $5 \mathrm{a}$ and $b$ ). This is the result of not uniform thickness due to less controlled MOCVD deposition conditions. ZnO nanorods, in addition, show a great size dispersion and a decreased density.

Nanorods length has also been tailored by changing the nutrient bath concentrations [26], namely, by increasing the Zn acetate and TMEDA concentrations, keeping constant the (TMEDA/ $/ \mathrm{n}^{2+}$ ) ratio. It is evident that CBD growth (on $\mathrm{ZnO}$ buffer layer deposited at $500{ }^{\circ} \mathrm{C}$ for $30 \mathrm{~min}$ ) promotes the formation of $\mathrm{ZnO}$ nanorods which growth rates, diameters and lengths vary upon changing the nutrient bath concentration ([TMEDA] $15 \mathrm{mM}, 25 \mathrm{mM}$ and $50 \mathrm{mM}$ ). In particular, the nanorods aspect ratio ( $\mathrm{AR}=$ length/diameter) increases upon increasing the concentration (Table 1) as shown in the prototypical SEM images reported in Fig. 8. This observation agrees well with a prevalent c-axis orientation vs a lateral growth. Moreover, there is an evidence that lower TMEDA concentrations $(15 \mathrm{mM})$ result in nanorod arrays of greater density (Fig. 8a and b) compared to higher concentrations ( $50 \mathrm{mM}$ ) (Fig. $8 \mathrm{c}$ and d). It is worth noting that the higher precursor concentrations per unit area seem to promote the growth of nanorods, having a larger diameter, as a possible consequence of coalescence phenomena.

The XRD patterns (Fig. 9) agree with the crystalline nature of the nanorods with predominant c-axis orientation as the nutrient bath concentration is increased.

Finally, it has been demonstrated that, at higher concentration $(50 \mathrm{mM})$, the CBD growth rate is strongly enhanced $(\sim 600 \mathrm{~nm} / \mathrm{h})$ over low temperature deposited $\left(400{ }^{\circ} \mathrm{C}\right.$ ) seed layer (see Fig. 10a and b) compared to lower concentration $(25 \mathrm{mM})$ counterpart $(\sim 200 \mathrm{~nm} /$ h, see Fig. $5 a$ and $b$ ).

Photoluminescence measurements provide important information about the crystal quality of $\mathrm{ZnO}$ nanostructures. The optical response of $\mathrm{ZnO}$ nanorods obtained by combining $400{ }^{\circ} \mathrm{C}$ seed layer and faster CBD deposition conditions (TMEDA $50 \mathrm{mM}$ ) (Fig. 10) has been studied. Fig. 11 shows the related room-temperature photoluminescence $(\mathrm{PL})$ spectra. The poorly crystalline seed layer presents a wide, weak ultraviolet band-edge emission peak centred at $\sim 390 \mathrm{~nm}$. After the $\mathrm{CBD}$ growth and despite the poor $\mathrm{ZnO}$ nanorod alignment (Fig. 10), photoluminescence measurements show a strong UV emission at $377 \mathrm{~nm}$ along with a weak and broad green emission around $550 \mathrm{~nm}$ (Fig. 11). The band-edge emission is typically related to recombination of free excitons [27], whilst the visible green emission is associated with the structural defects of oxygen vacancies [28].

The band-edge emission peak is very sharp and narrow $(\mathrm{FWHM}=14 \mathrm{~nm})$ and the large intensity ratio of UV to green PL points to the high crystal quality of $\mathrm{ZnO}$ nanorods, despite the low crystallinity of the seed layer. In fact, the relative high PL intensity

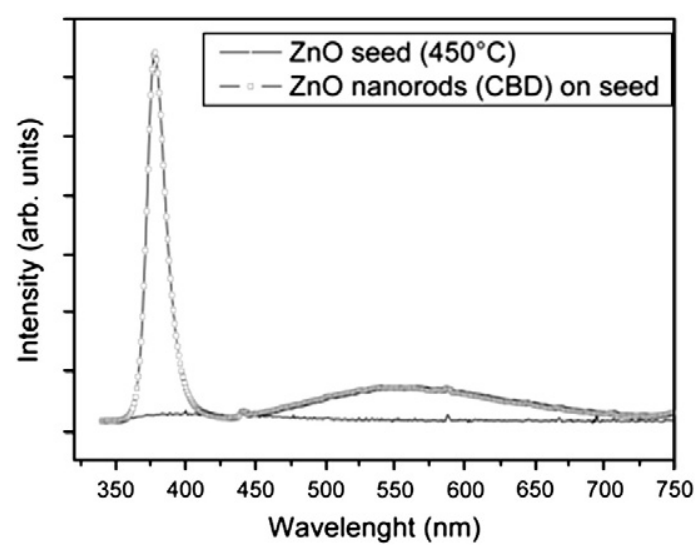

Fig. 11. PL spectrum of $\mathrm{ZnO}$ nanorods grown by $\mathrm{CBD}(50 \mathrm{mM}, 2 \mathrm{~h})$ on seed layer deposited at $400{ }^{\circ} \mathrm{C}$. 
ratio between the UV and green emissions indicates that $\mathrm{ZnO}$ nanorods have low concentration of deep level defects [5,22,29,30].

It can be concluded that higher concentration of CBD bath can improve the crystal quality, growth rate and optical properties of the corresponding $\mathrm{ZnO}$ nanorods, despite the crystal quality of the $\mathrm{ZnO}$ seed layer.

\section{Discussion}

In this study, the effects of several different $\mathrm{ZnO}$ seed layers, deposited by MOCVD, on the CBD growth of homologous $\mathrm{ZnO}$ nanorods have been investigated. Density, size, and growth rate have been studied. The results provide an evidence of slower growth rates upon increasing the overall roughness and morphological complexity of seed layers. Meanwhile, the density of nanorods per unit area is larger as a consequence of smaller diameter values. Of course, greater morphological complexities of the seed layers involve a large number of nucleation sites that can be accessed by the $\mathrm{ZnO}$ precursor in the CBD solution. In this case, the local precursor $\left(\mathrm{Zn}^{2+}\right.$ and $\mathrm{OH}^{-}$) concentration at the solution-substrate interface is decreased, thus slowing down the overall growth rate. In fact, $\mathrm{ZnO}$ amorphous seed layers deposited by drop casting [19] have greater CBD growth rates than those deposited over the crystalline substrates. It, therefore, transpires that, at higher nucleation densities, the gradient concentration experienced by each nucleation site fall-off, thus producing shorter and thinner nanorods.

The seed layer characteristics also affect the alignment of the $\mathrm{ZnO}$ nanorods. Poorly crystalline and not oriented seeds induce the growth of slanted nanorods, having, in addition, greater dispersion of dimensions. As already observed, the thickness of the seed is an additional factor that impacts on the overall quality of the $\mathrm{ZnO}$ nanorods and on the related growth rates. In particular, greater growth rates are observed in the case of thinner seed layers [21]. In this context, MOCVD seed layers obtained at lower deposition temperatures $\left(300^{\circ} \mathrm{C}\right)$ or at shorter process times $(10 \mathrm{~min})$, are poorly uniform and therefore not suitable for high quality CBD ZnO nanorods growth.

The aspect ratio of $\mathrm{ZnO}$ nanorods grown in solution is governed by the relative growth rates of the polar [001] and of the non-polar [101] and [100] surfaces [5,31-33]. ZnO, in fact, exhibits partial polar characteristics, having the opposite ends of (001) plane positively $\left(\mathrm{Zn}^{2+}\right)$ and negatively $\left(\mathrm{O}^{2-}\right)$ charged and characterised by high surface energy. Non-polar planes are thermodynamically more stable and, hence, the CBD growth process favours nanorods growth along the [0001] direction where the large facets are usually the non-polar planes. Nanorods are, therefore, c-axis textured to minimise the exposed surface area of the polar facets and to reduce the surface energy.

Seed layers having higher roughness might, in addition, cause nanorods coalescence effects. In fact, not enough smooth (at the nanoscale level) substrates have nucleation seeds with the (001) planes not parallel to the substrate. Growing nanorods, therefore, mismatch the c-axial direction, merge with other nanorods and larger nanostructures are produced. For this reason, $\mathrm{ZnO}$ nanorods grown over flake-like substrates appear extremely slanted with coalesced nanostructures and a wide size distribution.

Precursor concentrations ( $\mathrm{Zn}$ acetate and complexing agent/base) in the nutrient bath are also critical factors to control the aspect ratio and surface density of $\mathrm{ZnO}$ nanorods [26]. Present data agree well with a trend [34] of increasing rates upon increasing the concentration with structures having a predominant c-axis texturing and greater aspect ratio (see Table 1 ).

Finally, higher bath concentration $(50 \mathrm{mM})$ results in faster $\mathrm{ZnO}$ nanorods growth rate on less crystalline seed layers $\left(400{ }^{\circ} \mathrm{C}\right)$. In particular, it has been demonstrated how growth rate increases from $\sim 200 \mathrm{~nm} / \mathrm{h}$ to $\sim 600 \mathrm{~nm} / \mathrm{h}$ upon varying the bath concentration from $25 \mathrm{mM}$ to $50 \mathrm{mM}$.

Present $\mathrm{ZnO}$ nanostructures have also a strong UV emission and may represent important materials in optoelectronics. In fact, the optical qualities of the $\mathrm{ZnO}$ nanorods have been tested and good performances were found for the structures grown on low temperatures seed layer $\left(400{ }^{\circ} \mathrm{C}\right)$ using a high CBD bath concentration $(50 \mathrm{mM})$. It is worth noting that the UV emission peak is very sharp and has a narrow full width at half-maximum $(F W H M=14 \mathrm{~nm})$. The predominance of the UV peak over the weak green band $\left(\mathrm{I}_{\mathrm{UV}} / \mathrm{I}_{\mathrm{Green}}=10\right)$ provides a clear evidence of the high optical and crystalline quality of the $\mathrm{ZnO}$ neo-formations $[5,22,29,30]$, despite their poor vertical alignment.

\section{Conclusion}

A two steps MOCVD-CBD approach is presented as a strategy to fabricate c-axis oriented $\mathrm{ZnO}$ nanorods. Effects of the $\mathrm{ZnO}$ buffer layer, deposited by MOCVD, on the subsequent CBD growth of $\mathrm{ZnO}$ nanorods have been scrutinised. The thickness and structural complexity of the $\mathrm{ZnO}$ buffer layer has a great impact on the nanorods growth rate and greater surface roughness slow down the $\mathrm{CBD}$ growth. In fact, the $\mathrm{ZnO}$ buffer layer acts as a nucleation template for the $\mathrm{ZnO}$ nanorods growth and, hence, more complex templates have more $\mathrm{ZnO}$ nuclei that favour a higher $\mathrm{ZnO}$ nanorods density. Nevertheless the corresponding growth rate appears slowed down due to an overall decrease of the $\mathrm{Zn}^{2+}$ and $\mathrm{OH}^{-}$concentration at the substrate-CBD solution interface.

Moreover, the good crystalline grade of seed layers appears strongly related to the MOCVD deposition temperature and represents an important parameter to improve texturing of $\mathrm{ZnO}$ nanorods.

Furthermore, the effect of nutrient bath concentration on $\mathrm{CBD}$ growth rate has been investigated. Lower nutrient bath concentrations are associated with slower $\mathrm{ZnO}$ growth rate. Upon increasing the concentration, the CBD process is faster and the global nanorods aspect ratio is increased thus supporting the preferential 1-D growth along the c-axis of the $\mathrm{ZnO}$ nanostructures.

Finally, it has been demonstrated that the present approach is effective to grow, even over low quality buffer layers, deposited via MOCVD at low $\left(400{ }^{\circ} \mathrm{C}\right)$ process temperature, long and crystalline $\mathrm{ZnO}$ nanorods possessing, at room temperature, a strong ultra-violet (UV) photoluminescence edge emission at about $3.28 \mathrm{eV}$ and a weak green contribution. This is the evidence of limited defect densities of the obtained $\mathrm{ZnO}$ nanostructures.

\section{Acknowledgements}

Authors would like to acknowledge INSTM (Consorzio Interuniversitario Nazionale per la Scienza e Tecnologia dei Materiali) and ALADIN Industria 2015 project (Ministero dello Sviluppo Economico) for support to the present study. Professor Riccardo Reitano is also acknowledged for Photoluminescence analysis.

\section{References}

[1] A.I. Hochbaum, P. Yang, Chem. Rev. 110 (2010) 527.

[2] J.G. Lu, P. Zhang, Z. Fan, Mater. Sci. Eng. R 52 (2006) 49.

[3] L. Vayssieres, K. Keis, S.-E. Lindquist, A. Hagfeldt, J. Phys. Chem. B 105 (2001) 3350

[4] M. Guo, P. Diao, S. Cai, Appl. Surf. Sci. 249 (2005) 71

[5] L.E. Greene, M. Law, J. Goldberger, F. Kim, J.C. Johnson, Y. Zhang, R.J. Saykally, P. Yang, Angew. Chem., Int. Ed. 42 (2003) 3031.

[6] Z.R. Tian, J.A. Voigt, J. Liu, B. Mckenzie, M.J. Mcdermott, M.A. Rodriguez, H. Konishi, H. Xu, Nat. Mater. 2 (2003) 821.

[7] S.-C. Liou, C.-S. Hsiao, S.-Y. Chen, J. Cryst. Growth 274 (2004) 438.

[8] T. Ma, M. Guo, M. Zhang, Y. Zhang, X. Wang, Nanotechnology 18 (2007) 035605.

[9] L.E. Greene, M. Law, D.H. Tan, M. Montano, J. Goldberger, G. Somorjai, P. Yang, Nano Lett. 5 (2005) 1231.

[10] D. Byrne, E. McGlynn, M.O. Henry, K. Kumar, G. Hughes, Thin Solid Films 518 (2010) 4489. 
[11] G. Kenanakis, D. Vernardou, E. Koudoumas, N. Katsarakis, J. Cryst. Growth 311 (2009) 4799.

[12] S.-H. Hu, Y.-C. Chen, C.-C. Hwang, C.-H. Peng, D.-C. Gong, J. Alloys Compd. 500 (2010) L17.

[13] C.-C. Ting, C.-H. Li, C.-Y. Kuo, C.-C. Hsu, H.-C. Wang, M.-H. Yang, Thin Solid Films 518 (2010) 4156.

[14] Y. Tao, M. Fu, A. Zhao, D. He, Y. Wang, J. Alloys Compd. 489 (2010) 99.

[15] T. Hamada, A. Ito, E. Fujii, D. Chu, K. Kato, Y. Masuda, J. Cryst. Growth 311 (2009) 3687.

[16] C.M. Shin, J.Y. Lee, J.H. Heo, J.H. Park, C.R. Kim, H. Ryu, J.H. Chang, C.S. Son, W.J. Lee S.T. Tan, J.L. Zhao, X.W. Sun, Appl. Surf. Sci. 255 (2009) 8501.

[17] X.Q. Zhao, C.R. Kim, J.Y. Lee, J.H. Heo, C.M. Shin, H. Ryu, J.H. Chang, H.C. Lee, C.S. Son, W.J. Lee, W.G. Jung, S.T. Tan, J.L. Zhao, X.W. Sun, Appl. Surf. Sci. 255 (2009) 4461.

[18] G. Malandrino, M. Blandino, L.M.S. Perdicaro, I.L. Fragalà, P. Rossi, P. Dapporto, Inorg. Chem. 44 (2005) 9684

[19] M.E. Fragalà, Y. Aleeva, G. Malandrino, Superlattices and Microstructures 48 (2010) 408.

[20] W.-Y. Wu, C.-C. Yeh, J.-M. Ting, J. Am. Ceram. Soc. 92 (2009) 2718.
[21] J. Song, S. Lim, J. Phys. Chem C 111 (2007) 596.

[22] W. Wu, G. Hu, S. Cui, Y. Zhou, H. Wu, Cryst. Growth Des. 8 (2008) 4014.

[23] G. Malandrino, M. Blandino, M.E. Fragalà, M. Losurdo, G. Bruno J. Phys. Chem. C 112 (2008) 9595

[24] Y.-C. Lee, S.-Y. Hu, W. Water, K.-K. Tiong, Z.-C. Feng, Y.-T. Chen, J.-C. Huang, J.-W. Lee, C.-C. Huang, J.-L. Shen, M.-H. Cheng, J. Lumin. 129 (2009) 148.

[25] X. Gao, X. Li, W. Yu, J. Phys. Chem. B 109 (2005) 1155.

[26] K. Govender, D.S. Boyle, P.B. Kenway, P. O'Brien, J. Mater. Chem. 14 (2004) 2575.

[27] B.D. Yao, H.Z. Shi, H.J. Bi, L.D. Zhang, J. Phys. Condens. Mater. 12 (2000) 6265

[28] K. Vanheusden, W.L. Warren, C.H. Seager, D.R. Tallant, J.A. Voigt, B.E. Gnade, J. Appl. Phys. 79 (1996) 7983

[29] A.B. Djurišić, Y.H. Leung, Small 2 (2006) 944

[30] P. Jiang, J.J. Zhou, H.F. Fang, C.Y. Wang, Z.L. Wang, S.S. Xie, Adv. Funct. Mater. 17 (2007) 1303.

[31] R.A. Laudise, A.A. Ballman, J. Phys. Chem. 64 (1960) 688.

[32] W.-J. Li, E.-W. Shi, W.-Z. Zhong, Z.-W. Yin, J. Cryst. Growth 203 (1999) 186

[33] K. Jacobs, D. Balitsky, P. Armand, P. Papet, Solid State Sci. 12 (2010) 333.

[34] Q. Li, J. Bian, J. Sun, J. Wang, Y. Luo, K. Sun, D. Yu, Appl. Surf. Sci. 256 (2010) 1698. 